\title{
Zinc-deficiency dermatitis in breast-fed infants
}

\author{
Antonia Kienast - Bernhard Roth • Christiane Bossier • \\ Christina Hojabri • Peter H. Hoeger
}

Published online: 10 May 2007

(C) Springer-Verlag 2007

\section{Erratum to: Eur J Pediatr}

\section{DOI 10.1007/s00431-006-0218-9}

Unfortunately, the citation of an article in Ref. no. 23 was not correct.

The correct citation is Sievers E, Oldigs H-D, Dörner K, Schaub J (1992) Longitudinal zinc balances in breast-fed and formula-fed infants. Acta Paediatr 81:1-6

The online version of the original article can be found at http://dx.doi. org/10.1007/s00431-006-0218-9.

\footnotetext{
A. Kienast $\cdot$ P. H. Hoeger $(\square)$

Catholic Children's Hospital Wilhelmstift,

Liliencronstr. 130,

Hamburg 22149, Germany

e-mail: hoeger@kkh-wilhelmstift.de

C. Hojabri • P. H. Hoeger

Department of Dermatology, Division of Paediatric Dermatology,

University of Hamburg,

Hamburg, Germany

B. Roth - C. Bossier

Department of Neonatology, University of Cologne,

Children's Hospital,

Cologne, Germany
} 